\title{
The Development Of Instructional Module Of Hybrid Approach Using Collaborative And Metacognitive (HybCoMet) Strategy As An Alternative Approach To Help Improving Generic Skills Among Students In Malaysian Polytechnics
}

\author{
Yusmarwati Yusof, University of East London, United Kingdom
}

\begin{abstract}
This paper presents the development and design of a new alternative approach to teaching, which is referred to as a hybrid teaching approach. This teaching approach is developed to meet the challenges and academic needs of students learning technical subjects at polytechnic level in Malaysia. It is intended to help students improve their learning and deepen their understanding in learning the subjects matters. It is also to help students to emphasize positive attitudes in a wide range of skills that are critically needed in a workplace such as communication, thinking and interpersonal skills (Yusof, 2004). Accordingly, this paper describes a "hybrid" educational system which integrates collaborative and metacognitive strategies, involving the development, design and implementation of an instructional module which is entitled "A Hybrid Approach Using Collaborative and Metacognitive (HybCoMet) Strategy: An Instructional Module for Polytechnics Lecturers". The HybCoMet Instructional Module is designed as an alternative to the current teaching approaches which are hereinafter referred as 'traditional approaches'. The strategy is intended to help students to learn in a meaningful way, by facilitating the assimilation of their knowledge prior to transfer it into real world situation. The purpose of the teaching module of HybCoMet Strategy is to encourage teachers to move away from the current teaching approach by which students are 'fed' facts and information (Wee, 2004). Even where there are some activities in a classroom, the teacher retains control over the procedure and learning process. Introducing HybCoMet strategy may allow teachers to experience a new role, as a facilitator who provides support and assistance and interferes only when necessary. The strategy could be beneficial for teachers preparing a lesson and was more effective at pointing teachers toward individual learning objectives. Therefore, it is expected that students could take control of the learning process and become more motivated and responsible for their own learning, and then will be able to prepare them for their future life. It was hoped to inculcate this learning mode into students' educational environment to prepare them for real-life situations and provide opportunities for the optimal intellectual and academic development as well as their generic skills. The designed instructional module is hoping will contribute as a new pedagogical approach to the representation of hybrid system for technical education needs at the polytechnics level and supply as a comprehensive academic references and guidelines to the academician and will be beneficial to those who are interested.
\end{abstract}

Keywords: Teaching approaches, collaborative learning, metacognitive strategies, hybrid approach/system, instructional module, generic skills.

\section{INTRODUCTION}

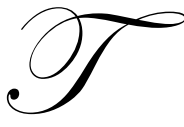

his paper focuses on the creation of a hybrid learning environment in an engineering subject in Malaysian polytechnics to enhance students' achievement, as well as enhance students' problem solving, critical thinking and communication skills, and team building. These skills are critically 
needed in the workplace of the $21^{\text {st }}$ century, and, on paper, Malaysian polytechnics are utilizing a variety of strategies to ensure that their graduates are competent for the workplace. But those skills were found sorely lacking in today's graduates as reported recently by Yusof (2004). In his paper, Yusof (2004) reported that students in Malaysian universities find it difficult to acquire the required amount of knowledge effectively and therefore do not reach higher order cognitive ability. They also lack important generic skills, such as communication, thinking and interpersonal skills. Thus, the need for a more in-depth study on teaching and learning to produce competent graduates at the polytechnic level, focusing in technical disciplines is required.

In my experience, our students expect us to "feed" them with the facts and information, and they subsequently 'regurgitate' what they have learnt in the examination. This kind of learning environment has the potential to turn the students themselves into passive recipients. They just wait for the information and knowledge to be delivered to them by the authority - the teachers. This learning environment actually inhibits the students and prevents them from expanding their creativity, oral communication skills, problem-solving ability and interpersonal skills. Those skills are probably urgently needed in society and highly demanded by employers, but many studies show that many graduates are found to be not suited to the jobs for which they applied because of their skill being less than satisfaction [Idrus (1992), McMurray \& Dunlop (1999), Simoff (2001), Neo (2003)]. We have to remember that the climate will not change until we make an effort to change it. Therefore it is vital to explore and describe the current approach to teaching that will promote a learning environment which may help students to improve their learning achievement as well as their attitudes and to prepare graduates to be more competent in the workplace. Some fundamental changes must be made in a way to approach the teaching and learning process as a mean to improve teaching and to increase learning by all students. Variety of approaches will be useful in upgrading students' understanding of learning concepts, and ultimately make the learning activities more meaningful to students (Tileston 2000).

Accordingly, the instructional module - a Hybrid Approach Using Collaborative and Metacognive Strategy has been developed to meet the challenges and academic needs of students learning technical subjects in Malaysian polytechnics. Collaborative learning and metacognitive strategies were combined and integrated in this module to become the hybrid system which is abbreviated to HybCoMet Strategy in this paper. The module was designed as an alternative pedagogical approach to the traditional approaches with the aim to help students to enhance their higher level of cognitive thinking while working as a group, and therefore could help students to improve their attitudes and generic skills in learning technical subjects.

The HybCoMet Instructional Module has been employed and tested to all first semester students undertaking three-years Civil Engineering Courses in 3 polytechnics in various states in Malaysia.

\section{LITERATURE REVIEW}

Malaysia is now faced with a reassessment of how education should be delivered to meet the needs of a changing economic order that will demand more skilled workers and knowledge workers; with more flexibility and therefore lifelong learning skills; and more self starters in a more autonomous and team spirited working environment such as independent learning and key skills (Maier and Warren, 2000). All of this results in a mass education system that is reassessing its learning and teaching practice and some of these experiences are reflected on teaching quality which leads to an increased awareness of how we teach. This situation makes me realize that some fundamental changes must be made in a way to approach the teaching as a means to improve teaching and learning process in the Malaysian polytechnic system that calls for a more effective structure of learning to respond to the changing needs of the new workforce.

Malaysian polytechnics have been established to provide broad-based industry-oriented technical education and training to post secondary school-leavers to impart the necessary competencies of technician and technical assistants in the various fields of engineering, junior-and middle level executives in the commercial and services sectors (Ahamad, 2002). The Malaysian Polytechnics system plays a large part within the Malaysian Education System, and continues to grow in order to meet the demand for skilled workers. The future of the country depends very much on the knowledge and skills acquired by the nation's youth today to face an increasingly competitive and challenging world of tomorrow. In order to survive, students must possess some skills, which are the key to their job 
survival. As such, the government has accorded high priority to education and skills training for youths, and the role and central goal of Malaysian Polytechnics to provide competent, flexible, motivated and responsible citizens as workforce for the nation with the possibility of further education and training (Sipon, 2003). Nevertheless, the Malaysian Education System has usually been designed with academically oriented with a focus on further studies but little focus on students' career aspiration (Idrus, 1992). This is becomes essential to help students understand a variety of issues that could help them face the challenge of working in today's globalization world. Students should find their learning more meaningful and they will need to see education as a continuing process in their lives that can prepare them for the future needs.

Through my experience while teaching in one of university in Malaysia, the education used to be a relatively simple affair - a teacher taught, students studied, and outcomes were assessed at a final examination. Tilestone (2000) stated that students deserve to be given meaningful, challenging work. It is an insult to give students mounds of dittos or meaningless busy work to fill up time. She added that learning in this new century will be less about reciting names, dates and places and more about critical thinking application such as problem solving, synthesis, creativity, analysis, and evaluation. But what currently happens in the education system, the approach is essentially teacher-centred and uses rote and fact-based learning. The teacher is in control of the classroom and decides what and how much information is to be disseminated to the students. The teacher creates the values, behaviours and beliefs for the students. These approaches also simplify relationships between teachers and taught because the teacher controls the learning process and students become passive recipients (Orlich et al., 1998 cited in Neo 2003). A majority of students fail to see such meaning in what they are asked to learn (Khair, 2004) and many teachers included myself are beginning to see the limitation in that current mode of teaching.

The system approach in polytechnics is concerned mainly with continuous system. In this system, the concept of learning is more to the traditional mode of instruction. In traditional instruction, content delivery is very much emphasized. Traditional instruction often utilizes one way communication media such as textbooks, OHP, real object/specimen, power point, and video tapes. Students are being taught what educational planners and educators think they need to know. Also, instruction is often delivered in a rigid, expository and passive manner (Meng, 2003). It needs to stress that, the way a person learns is very much affected by the learning environment $\mathrm{s} / \mathrm{he}$ is in. What an individual can learn, and how they learn it, depends on what model they have available.

As we shift to a new age and a vastly different approach in the way businesses operate, we must also shift our thinking and change our approach in teaching. As such, the traditional mode of teaching may not be effective anymore in meeting the demand of the new generation that requires higher analytical and cognitive skills. By asking myself "What needs to be changed?", "Have the objectives been met?", "What are the students reaction?" and "Was the content clear and did it enhance learning?" I provided myself with a basis for new approaches of the course. Based on this argument, I have been forced to think and consider the adoption of new innovative instruction approaches to enable learning to be carried out in a more effective and meaningful way. In particular, the design of HybCoMet strategy - which combines mix mode methods are being considered as one of the new learning approaches to replace the traditional system.

HybCoMet Strategy has been designed as an alternative approach in improving students learning because it is believed can help decrease the variability in finding relevant resources, providing a more consistent and predictable user experience (Deniman, 2003). In hybrid learning classroom, the learning of new concepts and the application of already-known concepts will take place primarily within the course. Here, learning takes place in a meaningful, authentic context and is a social, collaborative activity. The class is setting to which emphasized students involvement and group participant, which make students are less dependent upon teacher and they will learn how to learn. This will develop a sense of self confidence and independence in students, and thus become critical thinker. All these aspects are probably the most desirable skills which expected by employers. Therefore, it is essential for schools and institutions to be designed to be more career-oriented to help students acquire the necessary skills for the workplace. Thus, the hybrid system with the integration of collaborative learning and metacognitive strategies are being considered as the effective alternative approach which may help to enhance the students' learning process and provides opportunities for the development of students' generic skills and help to prepare them for the workplace. 
The term collaborative learning in this paper refers to an instructional method in which students at various performance levels work together in a small group to complete a task and achieve shared learning goals through interactive discussion (Ghokale, 1995). On the other hand, metacognitive strategies can be defined as the 'awareness and knowledge of one's mental processes such that one can monitor, regulate and direct them as a desired end' ((Mevarech \& Kapa, 1996). In this paper, matacognition is refers to mental operations that direct the cognitive functions of a person. Although collaborative learning is not a new topic, the idea of integrating metacognitive components will reinforce the importance of peer interaction for cognitive development. Gokhale (1996) believed that students are capable of performing a higher intellectual level when asked to work in collaborative situation than when asking to work individually. Group diversity in terms of knowledge and experience contribute positively to the learning process. Students can share strengths and also develop their weaker skills. They develop their interpersonal skills and learn to deal with conflict. When cooperative groups are guided by clear objectives, students engage in numerous activities that improve their understanding of subjects explored (Idrus, 1992).

Too much reliance on cognition and the brain cannot confirm how effectively students have learned and how active they are. For this reason, collaboration and metacognition are integrated to make sure that students engage in actions/activities while the brain is working to help them 'see' some of the thinking that should have occurred through learning and, as a result, students might be too busy to have a 'day dream'. In other words, this approach will allow students to actively engage their brain and, at the same time, engage their body, and it may assist the students to become more aware of their current attitudes towards the learning goal. The learning has the potential to become more meaningful and lasting through personal active engagement. Students should become aware of their thinking through peer interaction about the lesson, and then regulate their cognitive process to accomplish the shared goal. Hence, collaborative and metacognitive strategy have been chosen as components in the hybrid system which is believed can help students to enhance their higher level of cognitive thinking while working as a group (Haller et al 1998), and will make it possible for the students to internalize external knowledge, problem solving and critical thinking skills and to convert them into tools for intellectual functioning (McMurray \& Dunlop, 1999).

\section{THE DEVELOPMENT OF INSTRUCTIONAL MODULE OF HybCoMet STRATEGY}

This instructional module - the HybCoMet Strategy has been designed with the intention of helping those lecturers who may wish to promote new approaches, techniques and skills in their teaching practice and wish to help their students improve learning performance and achievement. It is also suitable for any cadre of readers seeking information and guidance on innovative techniques in teaching and learning. The primary purposes of this module, therefore, is to create a space for lecturers to experience and try out some alternative pedagogical approaches for implementing more active and meaningful learning which could be beneficial to the students.

The instructional module of HybCoMet Strategy is intended to give examples of ways in which to promote teaching and learning strategies that should motivate students and which may enhance their understanding in learning. To begin with, few objectives and purposes of the development of this module were highlighted. This module was designed for teachers with the intention of: (i) exploring collaborative learning activities;(ii) creating more active and challenging classroom activities;(iii) encouraging students in the development of critical thinking skills; (iv)supporting students in the development of good communication skills and self esteem; (v)helping students to be able to recall and apply their knowledge in the 'real world'; and (vi)preparing students for action - to get their brain into gear and move their body. (mentally and physically active)

Basically, the instructional module is constructed based on the selection of topics from the polytechnic curriculum. The subject that has been chosen is Concrete Technology, which is offered to First Semester Students in Civil Engineering Course, focusing on Topic 3- A Concrete Mix. Five learning tasks have been designed to cover this topic with HybCoMet Strategy. All the tasks attempt to accomplish the expected objectives of this topic as stated by the curriculum of polytechnics. All the tasks designed will aims to the development of communication, critical thinking, problem solving and team building skills. Several aspects have been taken into account in the process of developing the HybCoMet instructional module; group size, purpose of each activity, expected outcomes, time and duration of the activity, and how to evaluate and assess students' performance as an individual and also as a group (Barkley et.al, 2005; Kagan, 1994). All of these aspects are important considerations prior to the 
implementation of the module. Consideration on how students can analyze and reflect on what they have learned and to determine strengths and weakness of the new teaching strategies were highlighted as well.

To allow teachers and users apply the HybCoMet instructional module efficiently, the teaching module falls into three major parts. It is designed in this manner to provide a practical guide that allows teachers and users to experience and explore the HybCoMet Strategy, and help to deliver the strategy with systematically.

Part 1 with title 'From Me, To You, and For Us', is introduction to the theoretical basis, components, and the related instructional concepts of the HybCoMet Strategies. Here, the theoretical basis of the teaching approach and traditional approach are explained briefly. Collaborative learning and metacognitive strategies which are the main components of the approach are also being discussed in this part. Some suggestions on who will or can use the booklet, and a brief overview of how to use the booklet, and details of subject content are also covered in this part.

Part 2, 'Get Ready to Start' is intended to prepare readers and users to implement a new approach to teaching. It includes brief explanation of course subject, academic contents, learning and teaching strategies and also outline of activities and planning for classroom learning sessions using the hybrid approach. This part sets out all the information in a compact and accessible way for all levels of user-beginners, intermediate, advanced and also students.

The final part focuses on how to implement the HybCoMet Strategy in the classroom, which is called as 'Let's Start'. Here, the example of HybCoMet Strategy was outlined for the specific topics that have been chosen. This part is organized into five categories based on tasks. All of the tasks presented are intended to promote the development of generic skills: communication, problem solving, critical thinking skills and team building. Each task is identified by a simple description that gives a hint as to the purpose of the activity. All activities are explained in detail to help teachers deliver the task with confidence and increase prospect of success by the end of the learning session. At the end of each task, examples are provided on how to assess students.

This instructional module should provide users with a simple and flexible method that can be applied to a variety of disciplines and may help to achieve learning goals. All activities were designed in such a manner that requires users to be engaged in it actively and enables them to experience being an active learner. This experience might help users to encourage their students to engage in the same way. After reading and understanding this new approach, it is hoped that they are ready to start and apply the HybCoMet Strategy in their daily teaching practice and then be able to plan, design and deliver this approach for their own respective disciplines.

The module also contains a preface, a list of diagrams and tables, a section of references and an appendix. The explanation in every part is written simply using daily conversational language so that a lay person can easily understand and then adapt the concepts to their teaching practices. Furthermore, a target audience are teachers and lecturers in Malaysia, where English has become a second language. The teaching module has been organized to make it possible for the module to be used as a practical reference for lecturers.

\section{DATA COLLECTION AND FINDINGS}

To test a new alternative strategy, the HybCoMet Strategy, three groups of students from three different polytechnics in various areas in Malaysia have been chosen as a sample in the study. The samples comprised all the students undertaking three-years Civil Engineering Courses in one academic year (first semester). All groups were gone through their normal classroom learning session in the first half term and then continue their learning with the HybCoMet Strategy in the next half term. At this stage, survey using a set of questionnaire was distributed to identify how the approach may help to enhance students learning performance and increase their generic skills. After that, students will form back to their regular classroom structure and continue learning with the existing instructional delivery mode until the end of the term.

The questionnaire was grouped into four categories. Part A asking respondents' demographic details, which required them to choose the relevant answers that given in the sheet. Part B, C and D need respondents to response on course taken, subject matter, previous teaching approaches and the hybrid approach. These parts allow the 
respondents to react to 25 statements using a 5 - point Likert type scale ranging from strongly agree (SA) to strongly disagree (SD). Each item is given a weighted score with high score related to positive feelings.

After six weeks engaged in hybrid classroom learning session, students revealed that the strategy helped them to be more responsible to their learning and less dependent on the lecturer. They became more confident to talk in front of the class and felt more comfortable working as a group as this way helping them to share and generate ideas and at the same time handling criticism. They strongly agreed that the approach widened their knowledge in learning new topics as they had to refer to many sources outside the lecture room and thus they felt more ready to be involved in a real work place. By implementing HybCoMet Strategy, students were given a chance to 'show off' themselves during the learning session. Students gave a very positive feedback in almost all items that reflected application of this new strategy. They can work cooperatively and know their role very well.

With reference to the traditional approaches, students gave responses that they did not have much space to be active in classroom as they had to carefully listen and take notes that were displayed by the lecturers. Many activities conducted in the classroom were not really helping them to enhance communication, critical thinking, problem solving and team building skills. While the institutional ethos emphasizes the need to prepare the students for the future, the learning environment is not encouraging them to do that.

Nevertheless, there were few constraints faced by students while learning in hybrid classroom environment. They gave comments to the effect that the approach was too time consuming and burdensome with too much homework to accomplish every task. Lecturers needed to plan and manage time effectively since they can easily slip from the planned timetable.

\section{CONCLUSION}

Overall, it can be seen that students have very limited space to learn on their own and hardly have enough opportunities to 'show off' their mastery of learning content since lecturers controlled the classroom and showed their power in the process. By introducing the HybCoMet Strategy, students gave a feedback that hybrid classroom help to establish an atmosphere in which they felt more valued and more comfortable. The new approach had strengths in that it gave students the opportunity to contribute in solving problems. It also provided a meaningful context for learning fundamental concepts (Deniman, 2003). Above all, it helps students to think critically; solve complex problems; write and speak effectively; have respect for others; be able to adapt to change and be ready to engage in lifelong learning.

Hybrid system was chosen as an alternative approach in this paper because here, the learning of new concepts and the application of already-known concepts takes place primarily within the course and incorporated characteristics of both traditional and hybrid classroom settings. By implementing the HybCoMet Strategy, it is hoped, can challenge students in their learning so that, after finishing their studies, they will be able to manage a similar situation that may occur in their personal lives and also in the workplace.

I definitely do not recommend that this instructional module should be the only method used. I just hope that the examples that have been provided in this module may help teachers to incorporate some of the approaches into their regular teaching practise in order to become more 'colourful'. I intend and hope it will encourage students to improve their learning achievements as well as their attitudes and generic skills and to prepare them for real-life situations.

Further research needs to be conducted to identify how students could employ the hybrid learning experience in the real work place.

\section{REFERENCES}

1. Ahamad, S (2003). Educational Strategies for the K-Economy: Laying the Foundation for a Flexible and Competent Workforce. Journal of Technical Education, (2)1, 1-6 
2. Beverton, $\mathrm{S}$ et al, (2005). Teaching Approaches to Promote Consistent Level 4 Performance in Key Stage 2 English and Mathematics. A student thesis.

3. Deniman, D et al, (2003). Merging Metadata and Content-Based Retrieval. Journal of Digital Information, (4) $3,10-19$

4. Gardiner, L.F (1996) Why We Must Change : The Research Evidence. The NEA Higher Education Journal, (12)1, 71-82

5. Gokhale, A.A (1995). Collaborative Learning Enhances Critical Thinking. Journal of Technology Education, (7) 1, 53-60

Haller, E.P, Child, D.A, Walberg, H.J (1998). Can Comprehension Be Taught?: A Quantitative Synthesis of Metacognitive Studies. Educational Research, ( 17)9, 5-9.

6. Idrus, R (1992). Enhancing Tele-tutorials via Collaborative Learning. The Distance Education Online Symposium News, (14) 2.

7. Kapa, E (2001). A Metacognitive Support During the Process of Problem Solving in a Computerized Environment. Educational Studies in Mathematics, (47) 3, 317-336

8. Kjearsdam, F.\& Enemark,S (1995). The Aalborg experiment. Project innovation in University Education.Aalborg:Aalborg University Press.

9. Klein, B.S (1996). Learning Principles and Applications. McGraw Hill INC.

10. Maier, P and Warren, A (2000). Integrating Technology in Learning and Teaching: A Practical Guide For Educators. USA : Stylus Publishing Inc.

11. Mazzoni, G and Nelson, T.O (2000). Metacognition and Cognitive Neurophsychology: Monitoring and Control Processes. American Journal of Psychology, (113)1, 142-147

12. McClure, M.F (1990). Collaborative Learning : Teacher's Game or Students' Game? English Journal, (79) $2,66-70$.

13. McMurray, D.W \& Dunlop M.E (1999). The Collaborative Aspects of Online Learning. Paper Present at the $6^{\text {th }}$ International Literacy \& Education Research Network Conference on Learning, Bayview Beach Resort, Penang, Malaysia.

14. Neo, M (2003). Developing a Collaborative Learning Environment Using a Web-Based Design. Journal of Computer Assisted Learning, (19) 1, 462-473.

15. Phelps, R. Graham, A (2004). Teachers and ICT : Exploring a Metacognitive Approach to Professional Development. Australian Journal of Educational Technology. (20) 1, 49-68

16. Simoff, S. J (2001). Flexibility in Online Teaching and Learning Spaces. CAL-laborate Volume 7 October 2001.

17. Tileston, D.W. (2000). 10 Best Teaching Practices: How Brain Research, Learning Styles and Standards Define Teaching. California: Corwin Press, INC.

18. Walker, H. M (1997). Collaborative Learning: A Case Study for CS1 at Grinnell College and UT-Austin. Proceedings of the Twenty-eighth SIGCSE Technical Symposium on Computer Science Education, (13) 2, 209-213.

19. Wiener, H.S (1986). Collaborative Learning in the Classroom: A guide to Evaluation. Journal of College English, (48) 1, 52-56

20. Wiersma, M (1997). Research Methods in Education : An Introduction. Longman Group Ltd. London. Pg 323-343

21. Yusof, K. M (2003). Improving Teaching and Learning - Let's REACT, Journal of Technical Education, Ministry of Education, Malaysia, (2) 1, 7-16

22. Yusof, K. M (2004). Problem-based Learning: A Universiti Teknologi Malaysia Experience. Paper presented in Seminar On Problem Based Learning at KUiTTHO. 
NOTES 